\title{
GESTÃO PÚBLICA ESCOLAR E A NECESSIDADE DE COMBATE E PREVENÇÃO DO BULLYING DIANTE DA POSSIBILIDADE DE RESPONSABILIZAÇÃO DE PROFESSORES E INSTITUIÇÕES DE ENSINO' \\ http://dx.doi.org/10.5902/2176217115855
}

\author{
Wagner Augusto Hundertmarck Pompéo \\ Faculdade de Direito de Santa Maria, Brasil.
}

\begin{abstract}
Resumo
O bullying representa um dos maiores desafios a ser enfrentado pelos professores e gestores escolares. Isso ocorre pela falta de embasamento teórico e prático que permita a esses profissionais identificar sua ocorrência e saber como proceder em seu trato. $O$ público-alvo deste trabalho foram estudantes do Programa Especial de Formação de Professores para o Ensino Profissional da Universidade Federal de Santa Maria. Metodologicamente, a pesquisa pode ser classificada como quantitativa, conduzida mediante pesquisa survey com aplicação de questionário estruturado com doze perguntas de múltipla escolha e uma discursiva, opcional, em que a população de voluntários poderia narrar algum fato de bullying que tenha vivenciado. Os principais resultados encontrados demonstram que o bullying é prática comum no ambiente escolar, variando, entretanto, quanto ao gênero de suas vítimas ou agressores, formas de caracterização, local em que ocorre e consequências que despertam na psique do lesado. Concluiu-se que é necessário implantar política de gestão pública que se preocupe com a formação pedagógica dos atores escolares, os quais devem saber identificar e prevenir esta situação.
\end{abstract}

Palavras-chave: bullying, criança e adolescente, gestão pública, responsabilização.

\section{PUBLIC ADMINISTRATION AND THE NEED TO COUNTER AND PREVENT BULLYING CONSIDERING THE POSSIBILITY OF PROFESSORS AND EDUCATIONAL INSTITUTIONS HOLDING AFORESAID RESPONSABILITY}

\begin{abstract}
Bullying represents one of the greatest challenges professors and educational administrators have to address. This emerges in consequence of a theoretical and practical shortcoming of those professionals when identifying and handling bullying occurrences. The present work aimed for students in the Programa Especial de Formação de Professores para o Ensino Profissional of the Universidade Federal de Santa Maria. On a methodological approach, this research could be classified and quantitative. The conducted survey consisted of twelve multiple choice questions and one optional free response query in which the participants would narrate a personal bullying experience. The results showed how common bullying is inside the selected educational
\end{abstract}

\footnotetext{
1 Trabalho de conclusão apresentado para obtenção do título de especialista em Gestão Pública no Programa de Pós-Graduação em Gestão Pública da Universidade Federal de Santa Maria.

Regae: Rev. Gest. Aval. Educ. Santa Maria $\quad$ v. 4 n. 7 Jan./jun. 2015
} 
environment, in what manner it varies in between victim and perpetrator genres, its characteristics, where it takes place, as well as the aftereffects on the victim psyche. In conclusion it seems imperative to deploy a public administration policy which would focus on the pedagogical formation of educational actors who are furthermore obliged to identify and prevent the bullying situation.

Key-words: bullying, children and adolescents, public administration, responsibility. 


\section{Introdução}

$\mathrm{O}$ protagonismo ocupado pela escola e pelos professores é indiscutível. Enquanto processo de ensino e aprendizagem que é, a educação é um fenômeno exercido junto aos mais diversos espaços de convívio social, ocupando-se de transmitir às gerações que seguem modelos culturais de agir, ser e estar, necessários a convivência harmônica em sociedade.

Mais do que nunca, entretanto, a educação vem angariando um espaço cada vez maior nas mesas de debate e agenda destinadas a definir os rumos políticos da nova concepção de gestão pública que se busca alcançar.

Em vista dos inúmeros desafios que se apresentam e com vistas a um melhor desempenho e qualidade de resultado, esse novo paradigma, pensado à exaustão, enfatiza uma formação pedagógica mais robusta e que prepare melhor os professores e gestores de instituições de ensino a enfrentarem os novos problemas que têm surgido no espaço escolar.

Sem dúvida o bullying é um desses novos percalços, porque, ao ser caracterizado mediantes empurrões, fofocas, piadas e risos, é muito tênue a diferença que o separa de uma brincadeira de mau gosto, por exemplo. Isso porque, na grande maioria das vezes, aquela vem disfarçada mediante essa, fato que torna difícil sua identificação, trato e erradicação. Por isso, partindo do pressuposto de que, na imensa maioria das vezes, os professores e gestores escolares não estão aptos a lidar com um problema tão delicado e subjetivo como esse, que o presente trabalho se justifica.

Não obstante, também porque devido à mobilização dos mais variados setores sociais em favor do reconhecimento pela legitimação de suas diferenças, as instituições de ensino precisam se tornar mais relevantes de seu papel estratégico na construção de uma consciência crítica acerca de assuntos como diversidade e direitos humanos.

Para tanto, é fundamental que professores e gestores escolares conheçam a origem, conceito e aspectos fundamentais do bullying. Mas não somente isso, pois é necessário despertar nesses profissionais também a consciência do que lhes é exigido pelo sistema jurídico que se aplica à matéria - Constituição Federal e Estatuto da Criança e do Adolescente.

O trabalho objetivou analisar a percepção de professores e gestores escolares do Programa Especial de Formação de Professores para o Ensino Profissional da Universidade Federal de Santa Maria sobre o tema para, com isso, destacar a necessidade de os professores e gestores escolares públicos terem maior preparo para lidarem com situações que encerram casos de bullying, sobretudo porque, mesmo que poucos deles saibam, há possibilidade concreta de responsabilização sua e de suas instituições de ensino.

\section{Professores, gestores e instituições de ensino: rumo a uma nova gestão pública}

O mundo contemporâneo atravessa uma radical transformação, sobretudo no que diz respeito a seus campos social e econômico. Nesse sentido tem-se exigido, até mesmo de instituições governamentais, a adoção de estratégias que permitam a todos se adaptar às novas realidades que tem surgido. 
Pérez Gomes (2001) salienta que o corpo docente, sempre que postado diante de questões atinentes a mudanças radicais, interligadas a culturas e valores, mostra-se isolado, deslocado, sem iniciativa e com práticas didáticas obsoletas. Por esse motivo a problematização do tema objeto do presente trabalho se justifica, pois, como acrescenta mencionado autor,

parecemos carecer de iniciativa para enfrentar novas exigências porque, afinal de contas, nos encontramos encurralados pela presença imperceptível e pertinaz de uma cultura escolar adaptada a situações pretéritas. A escola impõe lentamente, mas de maneira tenaz, certos modos de conduta, pensamentos e relações próprios de uma instituição que se produz a si mesma, independentemente das mudanças radicais que ocorrem ao redor. (Pérez Gómez, 2001, p. 11)

O professor deve estar atento à forma de fazer as correções pedagógicas, evitando ridicularizar, rotular, depreciar ou mostrar preferência por alguns em detrimento de outros (Chardin, 2006). Lobo (1997, p. 91), corrobora dizendo que "a critica injusta é uma das formas de má comunicação, que provoca ressentimento, hostilidade e deterioração de desempenho".

Nesta perspectiva, convém argumentar que o professor é "ator no sentido forte do termo, isto é, um sujeito que assume sua prática a partir dos significados que ele mesmo Ihe dá, um sujeito que possui conhecimento e um saber-fazer provenientes de sua própria atividade e a partir dos quais ele a estrutura e a orienta" (Tardif, 2002, p. 230).

Quando o assunto é o bullying é necessário conceber um novo modelo de gestão pública ${ }^{2}$ focado, mais do que nunca, na figura do gestor público e seus partícipes, capitais humanos considerados chave essencial para a mudança, verdadeira e efetiva, que se quer ver.

É sob esse mesmo raciocínio que Maria Arlete Duarte Araújo (2010, p. 145) destaca a participação dos agentes sociais como sendo uma das principais características do que chama de "nova gestão pública". Nova gestão pública essa que se sustenta sob o argumento fundante de um movimento de modernização que tem por objetivo alterar o sistema educacional "em todas as suas instâncias, abarcando os níveis macro (ministérios), intermediário (secretarias estaduais e municipais de educação) e micro (escola) dos sistemas de ensino" (Cabral Neto, 2009, p. 196). Por isso que essa concepção adquire especial relevo no que diz respeito ao espaço público escolar, onde são muitos os aspectos que reclamam especial atenção e tratamento por parte do administrador público.

Não há dúvidas que o primeiro passo para contribuir com a melhoria da qualidade de ensino no Brasil é reconhecer que nossas deficiências são, ainda, plurais. Seja sob o ponto de vista da infra-estrutura, seja pela parca remuneração que recebem os professores, o fato é que novos desafios surgiram e dentre eles se nota uma silenciosa e pacata prática discriminatória, que se denominou bullying.

\footnotetext{
2 "Lo cierto es que, como si de una fuerza de la naturaleza se tratara, la renovación de la gestión pública es algo imparable y está en pleno proceso de renovación. El mundo ha cambiado y la gestión pública no es una excepción. Usar los recursos públicos con la máxima eficiencia para lograr satisfacer las demandas de los ciudadanos, aprovechar las oportunidades de un mundo globalizado y competitivo para alcanzar sociedades más acordes con los deseos colectivos exige cambios, imaginación e innovación" (Lima, 2001,
} p. 12). 
Com efeito, de nada adianta evoluir em quesitos objetivos se, concomitantemente, não se municia os gestores e professores do sistema público de ensino no que concerne à prevenção e combate de casos de ordem subjetiva, como o bullying.

Dentre os inúmeros co-responsáveis pelo combate e erradicação do bullying, os professores são quem, de uma maneira mais direta, estão, pelo exercício profissional diário, ligados a essa realidade, de modo que é necessário prepará-los para lidar com essa não recente, mas agora acentuada situação.

Não se pode negar, portanto, que no quesito formação pedagógica "é preciso buscar a qualidade, e esta, de uma maneira ou de outra, se expressa nos resultados obtidos pela escola" (Vieira, 2005, p. 16). Desta feita, cresce a importância de uma gestão de resultados, considerada por Cabral Neto como a principal estratégia para fortalecer a efetividade das políticas públicas:

A gestão por resultados é preocupação recente no campo da política educacional. Por tempo considerável, essa se orientou para uma cultura de processos, remetendo para o presente o desafio de construir uma cultura de resultados [...]. Se, em passado recente, o foco concentrou-se sobre a democratização do acesso e da gestão escolar, uma vez consolidado tal processo, o imperativo da educação de qualidade se faz inadiável. (Vieira, 2005, p. 15)

Com isso, é preciso combater o que Torres (2003, p. 142) chama de "estreita visão da educação como conteúdos", ou seja, a antiquada noção que, acrescenta o autor, coloca o ensino apenas "como informação a ser transmitida e a aprendizagem como informação a ser assimilada".

Conhecer o que é e saber com combater o bullying é o papel dos professores de todas as idades, não sendo dever única e exclusivamente dos pais. Isso porque todos, e os próprios estabelecimentos de ensino, nos termos do art. 932, inciso IV do Código Civil, podem ser responsabilizados em caso de inércia ou omissão em casos assim capitulados. Tanto é que dado o progressivo aumento dos casos de bullying, que o Conselho Nacional de Justiça - CNJ - elaborou e distribuiu uma cartilha informativa sobre o assunto.

Segundo a cartilha Bullying, lançada em 2010, como parte do Projeto Justiça nas Escolas, do Conselho Nacional de Justiça, evidencia-se que

a escola é corresponsável nos casos de bullying, pois é lá onde os comportamentos agressivos e transgressores se evidenciam ou se agravam na maioria das vezes. A direção da escola (como autoridade máxima da instituição) deve acionar os pais, os Conselheiros Tutelares, os órgãos de proteção à criança e ao adolescente etc. Caso não o faça poderá ser responsabilizado por omissão. Em situações que envolvam atos infracionais (ou ilícitos) a escola também tem o dever de fazer a ocorrência policial. Dessa forma, os fatos podem ser devidamente apurados pelas autoridades competentes e os culpados responsabilizados. Tais procedimentos evitam a impunidade e inibem o crescimento da violência e da criminalidade. (CNJ, 2010, p.12)

Devido a essa imputação objetiva, urge a necessidade de repensar as práticas escolares, facultando-se sejam tomadas medidas de prevenção, tanto de iniciativa pública como, também, privada. A violência nas escolas tem sido diagnosticada de formada cada vez mais frequente, valendo considerar que por violência entendem-se ações que

\begin{tabular}{|l|l|l|l|l|l} 
Regae: Rev. Gest. Aval. Educ. & Santa Maria & v. 4 & n. 7 & Jan./jun. 2015 & p. 25-46
\end{tabular}


ofendem tanto a integridade física como a psíquica, pois "o medo, a tensão e a preocupação com sua imagem podem comprometer o desenvolvimento acadêmico, além de aumentar a ansiedade, insegurança e o conceito negativo de si mesmo" (Fante, 2005, p. 166).

Enquanto a violência física é infração que deixa vestígios, facilitando, por isso, sua identificação, a modalidade psíquica, por sua vez, paira as sombras de um agir dissimulado. Independentemente disso, Fante destaca que "as conseqüências para as vítimas desse fenômeno são graves e abrangentes, promovendo no âmbito escolar o desinteresse pela escola, o déficit de concentração e aprendizagem, a queda do rendimento, o absentismo e a evasão escolar (Fante, 2005, p. 44).

Na mesma linha, Marchesi (2006, p. 82) lembra que "as dificuldades emocionais dos alunos podem alterar suas relações sociais com professores e colegas e dificultar seriamente sua aprendizagem. Entre elas se encontram a percepção da falta de afeto, o isolamento social, a tristeza prolongada, o sentir-se marginalizado e maltratado."

O sistema de ensino brasileiro é, na atualidade, marcado por grandes diferenças, as quais também marcam o perfil dos estudantes e professores. Essa conjuntura de dados variam de região para região, revelando professores e alunos de todas as idades, todos propensos, por imersos no ambiente estudantil, a serem vítimas ou autores do bullying.

O desejo pela escolarização é aspecto que não mais se relaciona apenas com a juventude. Pelo contrário, vem crescendo em meio a pessoas de todas as idades, inclusive, nos idosos, o desejo em retomar os estudos, concluindo, não só o ensino fundamental e o ensino médio, como participando de programas oferecidos pelas instituições de ensino superior.

Assim vista, a escola se torna um espaço de encontro entre iguais, possibilitando a convivência com a diferença de uma forma qualitativamente distinta da família e, principalmente, do trabalho. Possibilita lidar com a subjetividade, havendo oportunidade para os alunos falarem de si, trocarem ideias, sentimentos. Potencialmente permite a aprendizagem de viver em grupo, lidar com a diferença, com o conflito, e, mais do que nunca, assumindo como pressuposto que os conhecimentos que cada aluno traz devem ser valorizados. A atitude do professor também mudou no sentido de que ele está aberto a instaurar uma relação mais democrática com o aluno, ainda que sem abdicar de um papel condutor do processo - com autoridade, mas sem autoritarismo (Dayrell, 1996).

Portanto, não restam dúvidas da imediatez de, por meio da implementação de um novo modelo de gestão pública escolar, trabalhar-se na formação pedagógica de professores e gestores escolares que se revelam pouco preparados para lidarem com assuntos ligados a situações de bullying, em especial por não saberem identificá-lo, vez que ignoram sua origem, conceito e aspectos fundamentais.

\section{Bullying: origem, conceito e aspectos fundamentais}

De acordo com Fante (2005), o termo bully, originário da língua inglesa, significa valentão. Encerrando conceito específico e muito bem definido, sua variação, que atende pelo nome de bullying, é pratica que já não se deixa mais confundir com outras formas de violência, apresentando características próprias e que, embora venha sendo estudada pelas mais distintas áreas do conhecimento humano, ainda é pouco conhecida por 
aqueles que tão importante papel tem no seu trato diário: os professores e gestores escolares.

Pelo conceito se descreve situações em que determinado agente se utiliza, sem motivo aparente, de práticas e atitudes agressivas com o intuito deliberado de causar sofrimento, angústia e dor a outrem. O bullying, em termos mais diretos, segundo Cleary, possui cinco características comuns:

Um comportamento deliberado (premeditado) para ofender e machucar; É repetitivo, freqüentemente durante um período de tempo. Para os agredidos, é difícil se defender. Para os que agridem, é difícil aprender novos comportamentos socialmente aceitos; A pessoa que pratica 0 bullying tem e exerce poder de forma inapropriada sobre a vítima. (Cleary, 2002, p. 3)

Na busca pela sua identificação no y educacional, Neto (2004) alerta para o fato de que

o bullying é classificado como direto quando as vitimas são atacadas diretamente, ou indireto, quando as vitimas estão ausentes. São considerados bullying direto os apelidos, agressões físicas, ameaças, roubos, ofensas verbais ou expressões ou gestos que geram mal estar aos alvos. São atos utilizados com uma freqüência quatro vezes maior entre os meninos. O bullying indireto compreende atitudes de indiferença, isolamento, difamação e negação aos desejos, sendo mais adotados pelas meninas. (p. 36)

Entretanto, existem situações distintas, em que se notam o que se convencionou chamar de "participantes indiretos" (Neto, 2004, p. 52). Isso se deve ao fato de que a forma como as pessoas reagem ao bullying permite classificá-los de quatro maneiras: (i) auxiliares (aqueles que participam de maneira a subsidiar, de alguma forma, a agressão); (ii) incentivadores (que acabam estimulam o autor na execução do ato); (iii) observadores (que, embora não participem, observam e se omitem em intervir); e, finalmente, (iv) os defensores (que protegem o alvo ou chamam algum adulto para intervir no caso).

Outro aspecto fundamental, e que às vezes confunde muitas pessoas, é o fato de que o bullying pode "ocorrer nas salas de aula, nos pátios escolares, na hora do intervalo e no momento de ir ou voltar da escola" (Gisi; Vaz; Valter, 2012, p. 2). Geralmente disfarçado, o bullying faz parte do cotidiano da maioria das salas de aula do Brasil e do mundo. Para Oliveira e Votre (2006),

a título de ilustração do caráter criativo e imagético do bullying, citamos o caso de uma menina, de boca acima do tamanho normal, que é chamada de vaso sanitário; de um garoto orelhudo, chamado de fusquinha de portas abertas; do garoto narigudo, que é o tromba de elefante; do menino portador de olheira funda, que é chamado de morreu; dos garotos com trejeitos afeminados, que são chamados de pit bitoca; das meninas com alguns traços masculinos, que são apelidadas de sapata, além dos apelidos clássicos, como Maria João. (Oliveira; Votre, 2006, p. 175)

Enquanto fenômeno premeditado e injustificado quanto a suas causas e consequências, por mais simples que possa parecer, fica claro que as chagas 
decorrentes do bullying perduram durante longo tempo junto ao psicológico da vítima, que, muitas vezes, passa a ter problemas pedagógicos acentuados.

Por essa diversidade de comportamentos que podem o caracterizar, aliado as consequências que têm para a formação psicossocial das crianças, que essas ações devem ser objeto de estudo. Existe a necessidade de formulação de políticas relacionadas à melhor preparação e formação de professores e gestores escolares que precisam, mais do que nunca, adaptarem-se as novas realidades sociais que diuturnamente a eles se apresentam.

É essa constatação que motivou o presente estudo, estabelecido em consequência das informações prestadas por professores e gestores escolares que, pela pesquisa opinativa, apontaram sua percepção e sentimentos diante da ocorrência de casos de bullying em escolas de educação pública em que tenham atuado.

Procurou-se trabalhar os principais dispositivos legislativos que dão suporte a compreensão da matéria - oriundos da Constituição Federal e Estatuto da Criança e do Adolescente, especialmente -, alertando a possibilidade da responsabilização jurídica daqueles profissionais em casos tais.

\section{A constituição federal e o estatuto da criança e do adolescente: a responsabilidade jurídica nos casos de bullying}

O direito, enquanto ramo autônomo que é, pode ser definido como a ciência que procura estabelecer um ponto de equilíbrio entre o relacionamento dos seres humanos e o ambiente em que vivem. Ao longo dos tempos, todavia, esse relacionamento sofreu - e continua diuturnamente a sofrer - inúmeras modificações, dadas as forças que lhe influenciam mutuamente, fazendo com que se obrigue a transformar-se junto com a sociedade.

Da mesma forma ocorreu com o bullying que, ao contrário do que muitos pensam, não é invenção de tempos modernos. Muito embora antes presente, há cerca de trinta anos que o tema passou a atrair a atenção de estudiosos de diversos campos das ciências sociais e humanas, recebendo a denominação específica pela qual é conhecido atualmente em todo o mundo e ocupando local de destaque em assuntos ligados, principalmente, as áreas da educação, direito e psicologia (Silva, 2010).

No Brasil, nas palavras de Silva (2010, p.16), "o atraso em identificar e enfrentar o problema foi enorme", sendo que foi somente a partir do ano 2000, quando Cleo Fante e José Augusto Pedra efetuaram pesquisa bastante abrangente, que o tema acabou por ser abordado de modo mais amplo. Apesar do conceito de bullying ser algo relativamente novo, o sistema jurídico brasileiro, em especial a Constituição Federal, que data do ano de 1988, revela-se bastante claro no que toca a possibilidade de responsabilização dos responsáveis por essa prática.

A Carta Magna, no art. 227, preceitua que

é dever da família, da sociedade e do Estado assegurar à criança e ao adolescente, com absoluta prioridade, o direito à vida, à saúde, à alimentação, à educação, ao lazer, à profissionalização, à cultura, à dignidade, ao respeito, à liberdade e à convivência familiar e comunitária, 
além de colocá-los a salvo de toda forma de negligência, discriminação, exploração, violência, crueldade e opressão. § 4.ํ A lei punirá severamente o abuso, a violência e a exploração sexual da criança e do adolescente. (Brasil, 1988)

Seguindo esse mesmo entendimento, a lei n. 8.069/90, mais conhecida como Estatuto da Criança e do Adolescente, exige, conforme redação de seu art. 6으, que classifica seus destinatários como sendo "pessoas em desenvolvimento", seja-lhes aplicada uma doutrina de proteção integral, em consonância com a redação de seus arts. $1^{\circ}$, $3^{\circ}$ e $4^{\circ}$, de modo que não se aceita, de maneira alguma, sejam eles vítimas de situações tais. O Estatuto da Criança e do Adolescente - ECA - tem como princípio que toda criança e adolescente tem direito à educação e, também, normatiza, no art. 5ํ, que "nenhuma criança ou adolescente será objeto de qualquer forma de negligência, discriminação, exploração, violência, crueldade e opressão, punido na forma da lei qualquer atentado, por ação ou omissão, aos seus direitos fundamentais" (Brasil, 1990).

Inúmeros instrumentos internacionais contemplam e respaldam os direitos humanos, dentre os quais se inserem, por óbvio, os das crianças e adolescentes. A exemplo, cita-se a Declaração dos Direitos Humanos e a Convenção Internacional de Direitos Humanos, mais conhecida como Pacto de São José da Costa Rica, que afastam qualquer espécie de tratamento cruel, desumano ou degradante ao ser humanos (Piovesan, 2014).

Diferente não é com a chamada Convenção sobre os Direitos da Criança que, datada de 20 de novembro de 1989, as garante, entremeio a dez princípios fundamentais: (i) direito à igualdade, sem distinção de raça, religião ou nacionalidade; (ii) direito a especial proteção para o seu desenvolvimento físico, mental e social; (iii) direito a um nome e a uma nacionalidade; (iv) direito à alimentação, moradia e assistência médica adequadas para a criança e a mãe; (v) direito à educação e a cuidados especiais para a criança física ou mentalmente deficiente; (vi) direito ao amor e à compreensão por parte dos pais e da sociedade; (vii) direito à educação e ao lazer infantil; (viii) direito a ser socorrido em primeiro lugar, em caso de catástrofes; (ix) direito a ser protegido contra o abandono e a exploração no trabalho; $(x)$ direito de crescer dentro de um espírito de solidariedade, compreensão, amizade e justiça entre os povos (Unicef, 1989).

Esses marcos normativos não deixam dúvidas: existe a possibilidade de impor responsabilização jurídica a todos aqueles envolvidos em casos de bullying. Pelo fato dessa responsabilização poder ocorrer, tanto mediante ação, quanto omissão, o tema virou prioridade no ambiente escolar, onde já se acumulam notícias que denotam muitos professores, gestores e instituições de ensino vêm sendo condenadas por serem negligentes em seu papel fundamental de, em sala de aula, diagnosticarem e coibirem ações dessa natureza.

Nesse sentido, tem-se caso ${ }^{3}$ ocorrido em Belo Horizonte, Minas Gerais, onde, mediante decisão da $15^{\mathrm{a}}$ Vara Cível do Tribunal de Justiça, uma instituição de ensino foi condenada a pagar indenização de dez mil reais a um aluno vítima de bullying, pois, entendeu-se provado que a vítima teve seu nome associado a mensagens difamatórias,

3 Por envolver menor de idade o processo se encontra em sigilo de justiça, não podendo ser referenciado seu número de autuação. Demais informações podem ser obtidas em inúmeras reportagens que foram veiculadas na internet, a exemplo das seguintes: CONJUR. Dano à Integridade - Colégio deve indenizar ex-aluno que sofreu bullying. 2013. Disponível em <http://www.conjur.com.br/2013-mai-19/colegiocondenado-indenizar-ex-aluno-sofreu-bullying $>$. Acessado em 16 abr., 2014. 
vexatórias e humilhantes publicadas junto a setor restrito do site da escola, cujos gestores escolares responsáveis, mesmo recebendo reclamação dos responsáveis do menor, nada fizeram.

Não o bastante, o processo logrou êxito em demonstrar também que, ao longo de sua trajetória estudantil, o menor havia sido vítima de reiterados atos de violência física e psicológica que, em essência, caracteriza prática de bullying (Conjur, 2013). Na decisão que reformou a sentença de primeiro grau, eis que inicialmente o pedido da vítima tenha sido negado, o desembargador Tibúrcio Marques destacou que estava demonstrado às várias agressões físicas e verbais de que foi vítima o menor. Acrescentou, ainda, que tais agressões se deram em sala de aula, praticadas por colega da vítima, fato que, por ir muito além de meros desentendimentos e atritos entre adolescentes, caracterizam o fenômeno denominado bullying (Conjur, 2013).

Desse modo, tem-se que as agressões vividas por essa e muitas outras possíveis vítimas Brasil afora, são passíveis de configurar situação de dano moral cuja responsabilidade é, muitas vezes, passível de ser atribuída a escola e seus gestores e professores. Isso se deve pelo fato de que tais figuras ou atores detém responsabilidade objetiva, que decorre da ofensa a integridade corporal ou à saúde da vítima. A escola deve desincumbir-se da função primordial de integrar socialmente seus destinatários, evitando, em contrapartida, sofram de agressões verbais, emocionais e física.

Quando não o faz, fica evidenciada esta a culpa da instituição de ensino que, ao não tomar as medidas destinadas a solução do problema ou tratamento adequado do caso, lesa um bem que era seu deve proteger, ou seja, a dignidade do menor, criança ou adolescente.

Por isso, é importante ter claro que sempre que omissos - a escola, seus gestores e professores -, possível será se falar não apenas em tutela jurídica civil, como também penal, uma vez que, muitas vezes, a conduta hostil pode se revelar como forma de crime contra a honra, lesão corporal, racismo ou, até mesmo, estupro, do mesmo modo que, por força dos artigos 186 e 927 do Código Civil (Brasil, 2002), imperativa a viabilidade de responsabilização civil, ocasião em que serão acionados os responsáveis pelo fato ou seus representantes.

Seguindo o raciocínio de que as ações decorrentes do bullying acabam por ofender bens juridicamente relevantes, resguardados pelo corpo constitucional ${ }^{4} \mathrm{e}$ internacional, ganha revelo a proposta do presente trabalho, ao considerar que os professores e gestores escolares também podem vir a ser responsabilizados ${ }^{5}$ por sua omissão em situações tais, nada mais pertinente do que viabilizar construir novas e inovadoras estratégias que permitam combater essa nova e verdadeira pandemia invisível que é o bullying.

\section{Modelo conceitual}

${ }^{4}$ Como tentativa de coibir a proliferação de ações dessa estirpe, o projeto de Lei $228 / 2010$, em tramite no Senado Federal, visa à inclusão junto a Lei de Diretrizes e Bases da Educação (Lei no. 9.394/96) de dispositivo que combata intimidações e agressões no ambiente educacional, a fim de que, a partir disso, vigore como verdadeiro instrumento de prevenção e repressão. Na Câmara dos Deputados a história não é diferente, existindo, atualmente, sete projetos em trâmite.

${ }^{5}$ A responsabilidade acerca do tema em comento, sob aspectos jurídicos, se faz solidária, a partir do momento em que a Lei impõe, concomitantemente, a mais de um agente, o dever de proteção a criança e ao adolescente. Isso denuncia, pois, o porquê o bullying vem sendo considerado um dos maiores problemas educacionais do novo século.

Regae: Rev. Gest. Aval. Educ. Santa Maria

v. 4

ก. 7

Jan./jun. 2015

p. $25-46$ 
O estudo buscou identificar a opinião de professores do Programa Especial de Formação de Professores para o Ensino Profissional da Universidade Federal de Santa Maria acerca dos seguintes aspectos do bullying: conceito, condutas que o caracterizam, frequência em que ocorre, envolvidos (agressores/vitimas), consequências e reações. Concedeu-se ainda, em uma única questão, a oportunidade de o público alvo discorrer a respeito de algum caso de bullying que tenha presenciado. $O$ questionário utilizado foi adaptado de Pereira de Andrade (2007).

Desse modo, a partir dos conceitos e informações revisados na fundamentação teórica e com base no estudo proposto, constrói-se o seguinte modelo conceitual.

Figura 1

Modelo conceitual do trabalho.

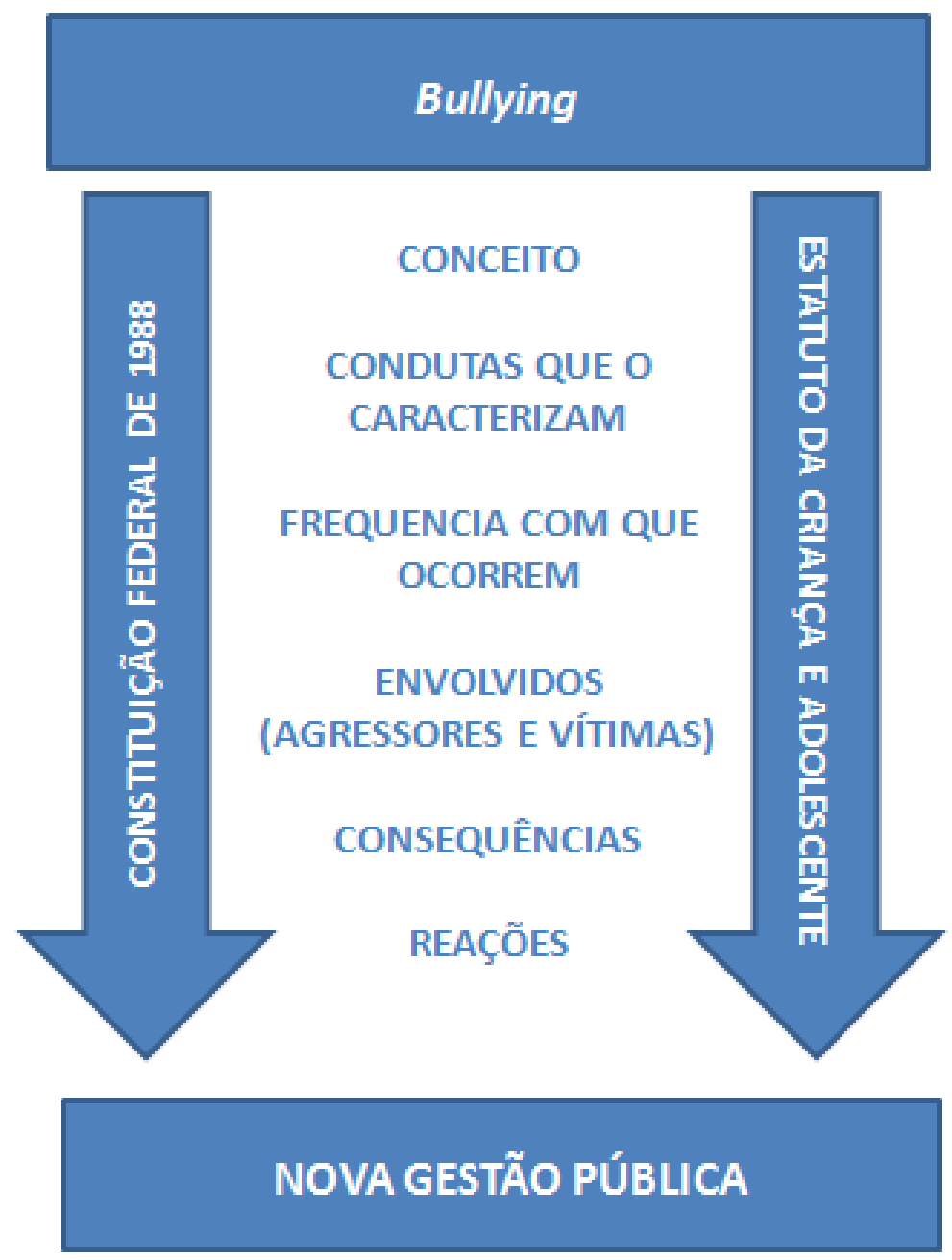

Para a realização desta pesquisa o universo do estudo foi constituído por estudantes que cursam algum dos três semestres do Programa Especial de Formação de Professores para a Educação Profissional da Universidade Federal de Santa Maria. Esse programa tem cerca de cinquenta alunos por turma e o objetivo geral de formar professores em nível superior para a docência na modalidade de Educação Profissional. 
A escolha desse público como alvo, preferencialmente a outros igualmente existentes, deu-se pelo fato do Programa ser formado de modo bastante heterogêneo, abarcando alunos das mais distintas áreas.

Para a execução do estudo usou-se amostragem não probabilística mediante processo dirigido a voluntários componentes da população antes delimitada, durante o período de 16 de abril a 16 de maio de 2014. Obteve-se 35 respostas que são analisadas a seguir.

\section{Resultados}

Com base nos dados obtidos na pesquisa survey, inicialmente são apresentados os resultados relacionados às características dos entrevistados: gênero, tempo de magistério, instituição e série que leciona, número de alunos das classes. Na sequência, são apresentados os resultados relativos ao tema em estudo, o bullying: conceito, condutas que o caracterizam, frequência em que ocorre, envolvidos consequências e reações e por fim será apresentado a análise dos resultados da questão aberta.

\section{Características dos respondentes}

No que se refere às características dos respondentes do questionário, verificou-se um relativo equilíbrio na questão de gênero, pois $45,7 \%$ dos respondentes são do gênero feminino, enquanto $42,9 \%$ são do gênero masculino. Obteve-se, ainda, $11.4 \%$ de não respostas a essa questão.

Com relação ao tempo de magistério, a faixa de tempo ficou situada entre seis meses a 41 quarenta e um anos de atuação, enquanto sua média, entretanto, foi de sete anos.

Desse modo, é possível analisar a percepção dos docentes das escolas, com diferentes níveis de experiência e maturidade. É importante destacar que houve número expressivo de respondentes que não responderam essa questão.

No que se refere à instituição de ensino onde os respondentes atuam, percebeu-se, igualmente, uma grande diversidade: Instituto Federal Farroupilha, Colégio PolitécnicoUFSM, Cietec, Cepesm, CS, SEG, Universidade Federal de Santa Maria, Fisma e Unopar. Além dessas instituições localizadas na região de Santa Maria, o estudo também contou com a participação de um respondente que atua em na Unicruz e outro no IFSC.

Ainda na caracterização, foram identificados também em qual nível de ensino os respondentes atuam. Nesse caso, $41,2 \%$ dos respondentes afirmaram atuar em cursos técnicos, enquanto os demais estão distribuídos entre o ensino médio e ensino superior, ou atuam em mais de um nível de ensino, fato que pode ser percebido no gráfico a seguir. 
Gráfico 1

Instituição de ensino em que atua.

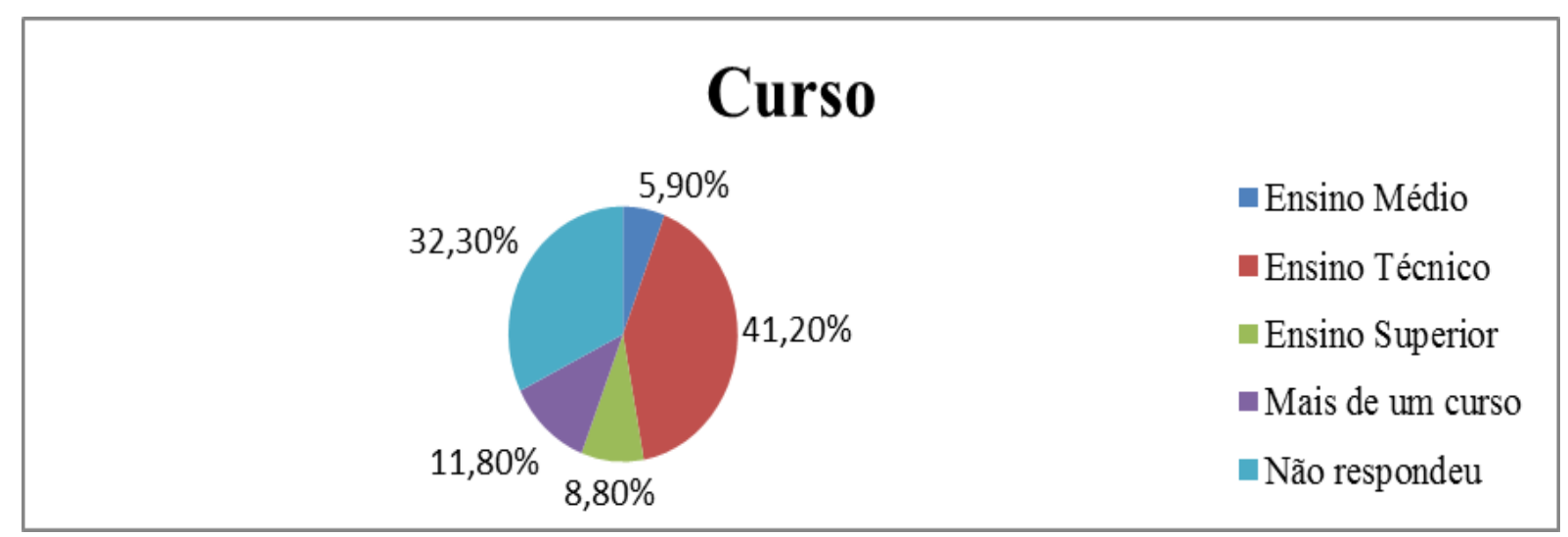

Fonte: Dados da pesquisa.

É importante referir que um número representativo de participantes não respondeu a essa questão, representando, juntos, $32,3 \%$ do total da amostra.

Por fim, em relação ao número de alunos das turmas em que os respondentes lecionam, a pesquisa chegou a uma média corresponde a 28 alunos por classe, conforme se nota da tabela a seguir.

Tabela 1

Número de alunos por turma.

\begin{tabular}{|c|c|}
\hline Valor & Número de alunos \\
\hline Média & 27,6 \\
\hline Número mínimo & 15 \\
\hline Número máximo & 40 \\
\hline Não responderam & 11 \\
\hline Total & 35 \\
\hline
\end{tabular}

Fonte: dados da pesquisa.

Os dados apresentados na tabela acima evidenciam que há uma grande variação em relação ao número de alunos com que cada respondente atua. Entretanto, com base no cenário que se tem hoje, considera-se normal essa diferença de número de alunos por classe de uma instituição a outra.

A seguir, serão apresentadas as estatísticas descritivas dos indicadores dos construtos: conceito, condutas que o caracterizam, frequência com que ocorre, envolvidos (agressores/vitimas), consequências e reações, e por fim a análise da questão aberta relacionada a relatos de casos de bullying presenciados pelos respondentes.

\section{Conceito sobre o tema bullying}

O conceito a respeito do tema bullying, que conforme Neto (2004), pode ser praticado na forma direta por apelidos, agressões físicas, ameaças, agressões verbais, e indireto, por meio de atitudes de indiferença, isolamento, difamação. Em relação ao conhecimento a respeito do tema $88,6 \%$ dos respondentes afirmaram já ter ouvido falar no assunto. 
Isso pode representar uma questão importante, pois ter esse conhecimento poderá facilitar a identificação e a tentativa de findar os casos de bullying.

\section{Condutas que caracterizam o bullying}

Ainda de acordo com as condutas mais incidentes percebidas pelos respondentes na sua escola, a maior parte delas está relacionada a maus tratos verbais e psicológicos, representando 54,3\% das respostas, a qual vai seguida da exclusão de grupo que, por sua vez, representou $20 \%$ das respostas obtidas, conforme exposto na tabela a seguir.

Tabela 2

Condutas mais incidentes.

\begin{tabular}{|l|c|c|}
\hline \multicolumn{1}{|c|}{ Tipos de condutas } & Frequência & Percentual \\
\hline Maus tratos verbais e psicológicos & 19 & 54,3 \\
\hline Maus tratos físicos & 2 & 5,7 \\
\hline Exclusão do grupo & 7 & 20,0 \\
\hline Não responderam & 7 & 20,0 \\
\hline Total & 35 & $100 \%$ \\
\hline
\end{tabular}

Fonte: dados da pesquisa.

Destaca-se, ademais, a incidência, embora em um índice menor, mas ainda assim preocupante, da existência de respostas que indicam também os maus tratos físicos como conduta incidente. Esse fato, por si só, chama a atenção para a necessidade de instigar uma conscientização em prol da não violência, além do desenvolvimento de ações e atividades que estimulem a formação de ambiente harmônico e seguro.

\section{Frequência com que ocorre o bullying}

Com relação à frequência em que os casos de bullying ocorrem houve relativa amplitude nas respostas. Enquanto $25.7 \%$ dos respondentes afirmam que esses tipos de incidentes ocorrem todos os dias, outros $20 \%$ dos respondentes afirmam que esse tipo de incidente ocorre uma vez por ano. Por outro lado, 25,7\% dos respondentes afirmam que incidentes como esse nunca ocorrem na escola, fato que permite dizer, portanto, que do total, $68,6 \%$ dos respondentes concordam que o bullying ocorre no mínimo uma vez por semana.

Tabela 3

Frequência com que ocorre.

\begin{tabular}{|l|c|c|}
\hline \multicolumn{1}{|c|}{ Frequência com que ocorre } & Frequência & Percentual \\
\hline Todos os dias & 9 & 25,7 \\
\hline Mais de duas vezes por semana & 3 & 8,6 \\
\hline Duas vezes por semana & 5 & 14,3 \\
\hline Uma vez por semana & 7 & 20,0 \\
\hline Nunca & 9 & 25,7 \\
\hline Não responderam & 2 & 5.7 \\
\hline
\end{tabular}

Fonte: dados da pesquisa 
Note-se que $5.7 \%$ dos pesquisados não responderam ou não souberam responder a essa pergunta.

\section{Envolvidos (agressores/vítimas)}

No que se refere aos envolvidos nos incidentes, gênero ou grupo de indivíduos que possuem um maior índice de envolvimento na prática do bullying, há uma grande variância dos dados, uma vez que $25,7 \%$ dos respondentes indicaram que os envolvidos estão concentrados em grupos mistos, 22,9\% afirmaram que o maior envolvimento é de grupos de meninos e 22,9\% dos respondentes indicaram que a participação é generalizada incluindo adultos, conforme dados expostos na tabela a seguir.

Tabela 4

Grupos com maior envolvimento.

\begin{tabular}{|l|c|c|}
\hline \multicolumn{1}{|c|}{ Grupos com maior envolvimento } & Frequência & Percentual \\
\hline Meninos em grupo & 8 & 22.9 \\
\hline Meninas em grupo & 3 & 8,6 \\
\hline Menino individual & 1 & 2,9 \\
\hline Participação generalizada incluindo adultos & 8 & 22,9 \\
\hline Grupo misto & 9 & 25,7 \\
\hline Não responderam & 6 & 17.1 \\
\hline Total & 35 & $100 \%$ \\
\hline
\end{tabular}

Fonte: dados da pesquisa.

Ressalta-se que um aspecto importante nessa questão foi o fato de que houve baixa incidência de meninos envolvidos na forma individual e, em paralelo, nenhuma incidência de menina envolvida individualmente.

Ainda no aspecto dos envolvidos, os fatores que os respondentes atribuem a agressão são, na maior parte, atribuídos à influência do meio, que representou $40 \%$ das respostas.

Tabela 5

Fatores que o originam.

\begin{tabular}{|l|c|c|}
\hline \multicolumn{1}{|c|}{ Fatores que o originam } & Frequência & Percentual \\
\hline Falta de estrutura familiar & 10 & 28,6 \\
\hline Agressores já foram agredidos & 2 & 5,7 \\
\hline Influência do meio & 14 & 40,0 \\
\hline Não responderam & 9 & 25,7 \\
\hline Total & 35 & $100 \%$ \\
\hline
\end{tabular}

Fonte: dados da pesquisa.

De acordo com a tabela 7 , o fator falta de estrutura familiar também obteve um valor relativamente significativo, representando $28,6 \%$ das respostas. No que se refere à identificação da maioria dos envolvidos em casos de bullying, vítimas, vítimas-agressoras ou agressores, $37,1 \%$ dos respondentes não souberam responder ou identificar, enquanto $22,9 \%$ afirmam que os envolvidos nos casos são vítimas, $20 \%$ afirmam que os envolvidos 
são vítimas-agressoras e, por fim, em um menor número, outros 8,6\% dos respondentes afirmam que a maioria dos envolvidos são agressores.

Em relação ao local onde esses casos de violência ocorrem, pode-se perceber, mais uma vez, que houve relativa variância, pois as três maiores frequências demonstram o bullying ocorre no pátio, nos corredores e na sala de aula da escola.

Tabela 6

Local em que ocorre.

\begin{tabular}{|l|c|c|}
\hline \multicolumn{1}{|c|}{ Local em que ocorre } & Frequência & Percentual \\
\hline Sala de aula & 6 & 17,1 \\
\hline Pátio & 12 & 34,3 \\
\hline Corredores & 7 & 20,0 \\
\hline Outros & 3 & 8,6 \\
\hline Não responderam & 7 & 20,0 \\
\hline Total & 35 & $100 \%$ \\
\hline
\end{tabular}

Fonte: dados da pesquisa

Conforme a tabela 8 , identifica-se que $34,3 \%$ dos respondentes afirmaram que os casos de bullying ocorrem no pátio da escola, enquanto $20 \%$ afirmaram ocorrem nos corredores e apenas $17,1 \%$ afirmam é a sala de aula a lugar de maior incidência de tais casos. Esses dados demonstram que é preciso desenvolver ações que estimulem sentimentos contrários a violência, principalmente no ambiente escolar.

No que se refere às agressões sofridas por alunos, há um índice maior de respostas referentes a agressões do tipo gozações, as quais representaram $28,6 \%$ das respostas.

\section{Tabela 7}

No que consiste o bullying sofrido por alunos.

\begin{tabular}{|l|c|c|}
\hline No que consiste o bullying sofrido por alunos & Frequência & Percentual \\
\hline Apelidos que incomodam & 6 & 17,1 \\
\hline Brincadeiras que causam aborrecimento & 5 & 14,3 \\
\hline Discriminações & 3 & 8,6 \\
\hline Gozações & 10 & 28,3 \\
\hline Comentários maldosos & 4 & 11,4 \\
\hline Não responderam & 7 & 20,0 \\
\hline Total & 35 & $100 \%$ \\
\hline
\end{tabular}

Fonte: dados da pesquisa.

Com o segundo maior índice, todavia, 17,1\% das respostas apontam as agressões do tipo apelidos e, como terceiro maior índice, aparece às agressões do tipo brincadeiras que causam aborrecimento. Conforme a maior parte das respostas, $71.4 \%$, pode-se também afirmar a maior parte dos agressores se encontram na mesma classe das vítimas.

Quanto aos aspectos físicos, chama-se atenção para a tabela a seguir. 
Tabela 8

Aspectos físicos.

\begin{tabular}{|l|c|c|}
\hline \multicolumn{1}{|c|}{ Aspecto físico } & Frequência & Percentual \\
\hline Mais velhos e mais fortes & 8 & 22,9 \\
\hline Mesma idade e fortes & 14 & 40,0 \\
\hline Mais novos & 3 & 8,6 \\
\hline Mais fracos & 1 & 2,9 \\
\hline Não responderam & 9 & 25,7 \\
\hline Total & 35 & $100 \%$ \\
\hline
\end{tabular}

Fonte: dados da pesquisa.

Como visto na tabela $10,62,9 \%$ dos respondentes afirmaram que os agressores possuem a mesma idade ou idade superior e são mais fortes que as vítimas, enquanto apenas 2,9\% dos agressores possuem um aspecto físico mais fraco e $8,6 \%$ são considerados mais novos.

\section{Consequências e reações}

Infelizmente a prática do bullying, muitas vezes, pode ser vista como um ato comum e sem muita importância, fato que pode trazer consequências ou reações ainda mais graves às vítimas, a ponto de lhes provocar tanto problemas emocionais e psicológicos, como também morais e físicos.

Em relação às emoções provocadas aquelas vítimas de casos de bullying, o sentimento de humilhação foi à questão mais evidenciada, representando $42,9 \%$ das respostas, como pode ser percebido na tabela a seguir.

Tabela 9

Emoções provocadas.

\begin{tabular}{|l|c|c|}
\hline \multicolumn{1}{|c|}{ Emoções provocadas } & Frequência & Percentual \\
\hline Chateadas & 3 & 8,6 \\
\hline Sem ter como impedir & 5 & 14,3 \\
\hline Humilhadas & 15 & 42,9 \\
\hline $\begin{array}{l}\text { Acham que é apenas brincadeira, não se sentindo } \\
\text { incomodadas }\end{array}$ & 1 & 2,9 \\
\hline $\begin{array}{l}\text { Não contam para ninguém sobre a incidência do } \\
\text { problema }\end{array}$ & 4 & 11,4 \\
\hline Não responderam & 7 & 20,0 \\
\hline Total & 35 & $100 \%$ \\
\hline
\end{tabular}

Fonte: dados da pesquisa.

Outros sentimentos com índices menores foram igualmente identificados, tais como, o de impotência $(14,3 \%)$, o de se sentir chateado $(8,6 \%)$ ou mesmo o fato de não falar para ninguém sobre a incidência do problema $(11,4 \%)$.

Para finalizar, também se observa as reações causadas pela prática do bullying que se encontram na tabela que segue. 
Tabela 10

Reações causadas pela prática do bullying.

\begin{tabular}{|l|c|c|}
\hline \multicolumn{1}{|c|}{ Reações } & Frequência & Percentual \\
\hline Alguém interfere & 4 & 11,4 \\
\hline Riem das gozações & 10 & 28,6 \\
\hline Não fazem nada & 13 & 37,1 \\
\hline Não responderam & 8 & 22,9 \\
\hline Total & 35 & $100 \%$ \\
\hline
\end{tabular}

Fonte: dados da pesquisa.

Conforme pode ser visto na tabela 12 , na maioria das vezes, a reação presenciada quando se tem um caso de bullying é "não fazem nada", representando $37,1 \%$ das respostas, sendo que em segundo lugar, aparece como reação o "riem das gozações", que atingiu o percentual de $28,6 \%$ das respostas.

Os dados demonstram, ainda, que o menor índice obtido a título de reação é aquele no qual alguém interfere na situação, o que corrobora, portanto, a perspectiva de que muitas vezes as pessoas não observam, não sabem como lidar ou acreditam se tratar de um ato comum que não merece interferência.

\section{Relatos de casos de bullying}

Com o objetivo de aprofundar o entendimento sobre esse tema, foi introduzida uma questão em que os respondentes poderiam relatar os casos de bullying que já teriam presenciaram.

Essa questão envolveu a participação de 17 respondentes, os quais representam $48,57 \%$ do total da amostra. Os principais aspectos abordados pelos respondentes nessa questão foram às formas de agressões. Grande parte dos relatos envolveram casos de agressões nas quais se vê o uso de algum tipo de apelido depreciativo, brigas em sala de aula, agressões físicas e psicológicas ou mesmo descriminações.

A seguir é apresentado um quadro onde se pode analisar alguns dos relatos considerados pertinentes ao presente estudo.

Quadro 1

Relatos sobre casos de bullying.

\begin{tabular}{|l|l|}
\hline Respondente & \multicolumn{1}{|c|}{ Relato } \\
\hline E20 & $\begin{array}{l}\text { Uma aluna chamou outro de gordo na sala de aula. O aluno } \\
\text { ofendido saiu da sala e desistiu do curso no mesmo dia. }\end{array}$ \\
\hline E24 & $\begin{array}{l}\text { Foi comigo mesmo. Recebi apelidos ofensivos, fui humilhado, } \\
\text { discriminado e mal-tratado pelos colegas da turma e da escola. } \\
\text { Os professores e a direção da escola não fizeram nada, inclusive, } \\
\text { riam juntos com os agressores. }\end{array}$ \\
\hline E10 & $\begin{array}{l}\text { Isolamento de colegas por opção sexual distinta, incluindo a } \\
\text { segregação do grupo maior daqueles que mantém } \\
\text { diálogo/aproximação com o discriminado. }\end{array}$ \\
\hline
\end{tabular}




\begin{tabular}{|l|l|}
\hline E13 & $\begin{array}{l}\text { O aluno esqueceu o facebook logado e um colega aproveitou } \\
\text { para publicar coisas obscenas por ele. }\end{array}$ \\
\hline
\end{tabular}

Fonte: dados da pesquisa.

Como se pode perceber no primeiro relato, há presença de apelidos maldosos referentes a aspectos físicos, a qual teve como consequência a humilhação e o desconforto da vítima que a levou a desistir do curso, fato que gera também uma consequência negativa para a própria instituição.

No segundo relato, o caso relatado ocorreu com o próprio respondente, que se disse humilhado e descriminado por colegas. Nesse caso, nota-se que não houve a interferência ou o controle dos responsáveis ou da direção da escola, os quais, segundo destacou o respondente, não tomaram nenhuma atitude e, pelo contrário, riram conjuntamente com os agressores. Esse caso corrobora os dados da pesquisa apresentada anteriormente, em que era muito pequeno o percentual de casos em que havia a intervenção de outras pessoas com vistas a cessar as agressões.

No terceiro caso percebe-se um ato que é muito comum e presente nos grupos e meios sociais: a descriminação pela opção sexual. Isso reporta à necessidade de desenvolvimento de campanhas que incentivem um comportamento correto e não preconceituoso, sob as mais distintas perspectivas que se possa ter em ambiente escolar.

$\mathrm{O}$ acesso à internet e a redes sociais, atividades que hoje, mais do que nunca, tornaram-se comuns no dia-a-dia dos indivíduos, também pode se tornar um meio para a prática bullying. Essa questão é evidenciada no quarto relato, no qual houve, além de agressão moral, uma invasão da privacidade da vítima. Essa questão impõe uma imediata reflexão sobre os desafios que o mundo virtual nos traz, bem como de que maneira se pode minimizar e evitar tais situações, as quais podem causar muito mais do que o mero constrangimento pessoal.

\section{Considerações finais}

Diante do exposto e considerada a possibilidade de responsabilização de professores e instituições de ensino quando da ocorrência de casos de bullying, concluise que é necessário que seja implementado um novo modelo de gestão pública escolar. Modelo esse que priorize a execução de ações aptas a formar professores que estejam pedagogicamente preparados para lidar com o bullying.

Se é sobre os ombros dos professores e gestores escolares que repousa, no fim das contas, a missão educativa da escola, são inaceitáveis os relatos reproduzidos junto a pesquisa realizada nesse trabalho ocorram a revelia de qualquer diagnóstico e interferência. É clara, assim, a necessidade de repensar, dentro do espaço educacional, formas de instigar os professores a debater a temática do bullying. Para tanto, é fundamental se propicie o "acesso a informação sob o fenômeno" (Gisi; Vaz; Valter, 2012, p. 2), pois a formação continuada exige os professores e gestores escolares possam, em um primeiro momento, identificar o problema para, a partir dele, definir o modo correto de agir, fazer o devido encaminhamento à sua resolução e, concomitantemente a isso, prevenir volte a ocorrer.

Dessa maneira, a escola estará capacitando seus profissionais, sejam professores ou gestores escolares, para que possam observar, identificar, diagnosticar, intervir e 
encaminhar casos tais às autoridades competentes quando necessário. Vale lembrar que a Constituição da República Federativa do Brasil, o Estatuto da Criança e do Adolescente, a Convenção sobre Direitos da Criança da Organização das Nações Unidas, asseguram o direito ao desenvolvimento e educação das crianças como algo fundamental. A adoção dos chamados diagnósticos de situação, melhoramento, supervisão e aprendizagem cooperativa e mesmo a intermediação de conversas entre agressores, vítimas e seus responsáveis são medidas igualmente válidas.

Louro (2003), por exemplo, compartilha desse mesmo pensamento ao destacar que, corriqueiramente os professores se sentem pouco à vontade quando confrontados com ideias de incerteza, tendo extremada dificuldade ao lidar com tais situações. E, de fato, as figuras escolares precisam estar preparadas para lidar com as novas perspectivas e desafios, de modo que, por isso, o sistema educacional deve ser articulado rumo a ações que contribuam, de maneira eficaz, ao seu enfrentamento. Por isso, partindo desse pressuposto e considerando tais figuras detém papel essencial no que diz respeito não apenas a aprendizagem escolar como também em questões sociais, é importante que se desenvolva novas ações e políticas que priorizem a formação e valorização dos profissionais da educação.

Elaborar e implantar oficinas ${ }^{6}$ que abordem a questões de bullying nas universidades, eventos científicos e em instituições educacionais, também pode ser importante passo rumo ao combate dessa pandemia invisível. Do mesmo modo, proporcionar momentos de aperfeiçoamento e troca de experiências, bem como quando sendo externadas posições frente às temáticas abordadas nas oficinas, estar-se-á ajudando a construir subsídios às novas abordagens das questões nos espaços escolares, bem como evitando que a ignorância, em alguns aspectos, acabe por sacramentar opiniões equivocadas como sendo absolutas e inquestionáveis verdades.

Assim, é de fundamental importância a efetivação de ações que busquem viabilizar aos professores e gestores escolares novas bases conceituais, sem olvidar, entretanto, do protagonismo que ocupa o poder público, a quem cabe, igualmente, reforçar e difundir as ideias e campanhas que, em nível nacional, regional ou local, devem procurar levar a todos a conscientização da necessidade de enfrentar, prevenir e erradicar o bullying.

Nesse ponto, a distribuição de cartilhas, como a produzida pelo Conselho Nacional de Justiça e disponível em http://www.cnj.jus.br/images/Justica nas escolas/ cartilha web.pdf é medida exemplar e que deve ser divulgada, trabalhada e discutida.

\section{Referências}

ANDRADE, Michela Pereira de. Bullying: concepções dos atores envolvidos. BAURU, 2007. Disponível em <http://www.fC.unesp.br/upload/pedagogia/TCC\%20Michela\%20\%20Final.pdf >. Acessado em 22 Mai. 2014.

\footnotetext{
6 As oficinas se mostram imprescindível à abertura de espaços de discussão entre futuros professores. Dessa forma, seus participantes apreendem a lidar com problemas, o que para Garcia (1997) é um processo intelectual, pois oferece múltiplas possibilidades de aprendizado por meio do desencadeio de inovadoras questões a serem trabalhadas ao redor do eixo que se propôs explorar. Isso por que "a perspectiva não disciplinar não descarta o conhecimento disciplinar, mas se insurge contra os efeitos de poder produzidos por ele. Principalmente o efeito do poder do especialista científico possuir esse conhecimento e negociá-lo dentro de uma economia em que os saberes científicos são qualificados e outros desqualificados" (Corrêa, 2000, p. 124).
}

\begin{tabular}{|l|l|l|l|l|l|}
\hline Regae: Rev. Gest. Aval. Educ. & Santa Maria & v. 4 & n. 7 & Jan./jun. 2015 & p. 25-46
\end{tabular}


ARAÚJO, Maria Arlete Duarte. Responsabilização da administração pública: limites e possibilidades do gestor público. CICLO DE PALESTRA ORGANIZADO PELA ESCOLA DE GOVERNO DO RN, 1, 2010. Anais ... Natal: Searh, 2010.

BRASIL. Constituição da República Federativa do Brasil. Brasília: Senado Federal, 1988.

BRASIL. Lei n. 10.406. Novo Código Civil Brasileiro. Brasília: Congresso Nacional, 2002.

CABRAL NETO, Antônio. Gerencialismo e gestão educacional: cenários, princípios e estratégias. In: FRANÇA, Magna; BEZERRA, Maura Costa (orgs.). Política educacional: gestão e qualidade do ensino. Brasília: Liber Livro, 2009, p. 169-204.

CHARDIN, Teilhard. O papel cognitivo e social da sensibilidade. In: ASSMANN, Hugo; CHAVES WM. Fenômeno bullying e a educação física escolar. ENCONTRO FLUMINENSE DE EDUCAÇÃO FÍSICA ESCOLAR, 10, 2006. Anais ... Niterói: UFF, 2006.

CLEARY Mark. Bullying information for schools. Disponível em: <http://www.police. govt.nz/service/yes/nobully/bullying info.pdf>. Acesso em: 15 mar., 2011.

CNJ. Bullying: projeto justiça nas escolas. Cartilha 2010. Disponível em $<$ http://www.cnj.jus.br/images/Justica nas escolas/cartilha web.pdf $>$. Acessado em 30 jan., 2014.

CORRÊA, Guilherme et al. Pedagogia libertária: experiências hoje. São Paulo: Imaginário, 2000.

CONJUR. Dano à integridade: colégio deve indenizar ex-aluno que sofreu bullying. 2013. Disponível em <http://www.conjur.com.br/2013-mai-19/colegio-condenado-indenizar-exaluno-sofreu-bullying $>$. Acessado em 16 abr., 2014.

DAYRELL, Juarez. A escola como espaço sócio-cultural. In: DAYRELL, Juarez (org.). Múltiplos olhares sobre a educação e cultura. Belo Horizonte: UFMG, 1996, p. 47-70.

FANTE, C. Fenômeno bullying: como prevenir a violência nas escolas e educar para a paz. Campinas: Verus, 2005.

GARCÍA, Eduardo; GARCÍA, Francisco Florentino. Aprender investigando: una propuesta metodológica basada em la investigación. Sevilla: Díada, 1997.

GERONASSO, Jociane Emídia Silva. Políticas e representações sociais de professores da escola básica sobre o bullying. SEMINÁRIO DE PESQUISA EM EDUCAÇÃO DA REGIÃO SUL, 9, 2012. Disponível em: <http://www.portalanpedsul.com.br/admin/ uploads/2012/Formacao de Professores/Trabalho/05 $47 \quad 33$ 1642-7223-1-PB.pdf>. Acesso em 15 abr., 2014.

GISI, Maria Lourdes; VAZ, Fabiana Andrea Barbosa; VALTER, Cristina Crescêncio Nabosne. Bullying: um desafio para a formação de professores. SEMINÁRIO DE PESQUISA EM EDUCAÇÃO DA REGIÃO SUL, 9, 2012. Disponível em $<$ http://www.portalanpedsul.com.br/admin/uploads/2012/Formacao de Professores/Traba lho/06 1544 2268-7092-1-PB.pdf >. Acesso em 15 abr., 2014.

LINHARES DA SILVA, Mozart. A urgência do tempo: novas tecnologias e educação contemporânea. In: LINHARES DA SILVA, Mozart (org.). Novas tecnologias: educação e sociedade na era da informática. Belo Horizonte: Autêntica, 2001, p. 39-56.

LOBO, Luiz. Escola de pais. Rio de Janeiro: Lacerda, 1997.

LOURO, Guacira Lopes. Currículo, gênero e sexualidade. In: LOURO, Guacira Lopes et al (orgs.). Corpo, gênero e sexualidade. Rio de Janeiro: Vozes, 2003, p. 59-76.

MARCHESI, Álvaro. O que será de nós, os maus alunos? Porto Alegre: Artmed, 2006. 
NETO, Aramis Lopes. Diga não ao bullying. Rio de Janeiro: Abrapia, 2004.

OLÍAS DE LIMA, Blanca. La nueva gestión pública. Madrid: Pearson Educación, 2001.

OLIVEIRA, Flávia Fernandes de; VOTRE, Sebastião Josué. Bulliyng nas aulas de educação física. Revista Movimento, Porto Alegre, v. 12, n. 2, 2006, p. 173-197.

PÉREZ GÓMEZ, Angel. A cultura escolar na sociedade neoliberal. Porto Alegre: Artes Médicas, 2001.

PIOVESAN, Flávia. Direitos humanos e o direito constitucional internacional. São Paulo: Max Limonad, 2014.

SILVA, Ana Beatriz Barbosa. Bullying: mentes perigosas nas escolas. Rio de Janeiro, Objetiva, 2010.

TARDIF, Maurice. Saberes docentes e formação profissional. Petrópolis: Vozes, 2002.

TORRES, Rosa R. Melhorar a qualidade da educação básica? As estratégias do Banco Mundial. In: TOMASSI, Livia de; WARDE, Mirian Jorge; HADDAD, Sérgio (orgs.). O Banco Mundial e as políticas educacionais. São Paulo: Cortez, 2003, p. 15-40.

UNICEF. Convenção sobre os direitos da criança. Portugal, 1990. Disponível em $<$ https://www.unicef.pt/docs/pdf publicacoes/convencao direitos crianca2004.pdf $>$. Acessado em 21 fev., 2014.

VIEIRA, Sofia Lerche. Gestão para uma comunidade de aprendizes: gestão escolar e qualidade da educação. Fortaleza: Seduc, 2005.

Wagner Augusto Hundertmarck Pompéo é bacharel em Direito, formado pela Faculdade Metodista de Santa Maria - Fames - e professor de Direito na Faculdade de Direito de Santa Maria - Fadisma.

Endereço: Avenida Osvaldo Cruz, 268 - 97095-470 - Santa Maria - RS - Brasil.

E-mail: wagner@fadisma.com.br.

Recebido em 12 de outubro de 2014.

Aceito em 7 de dezembro de 2014. 